\title{
A ciência da nutrição em trânsito: da nutrição e dietética à nutrigenômica
}

\author{
The science of nutrition in transit: from nutrition \\ and dietetics to nutrigenomics
}

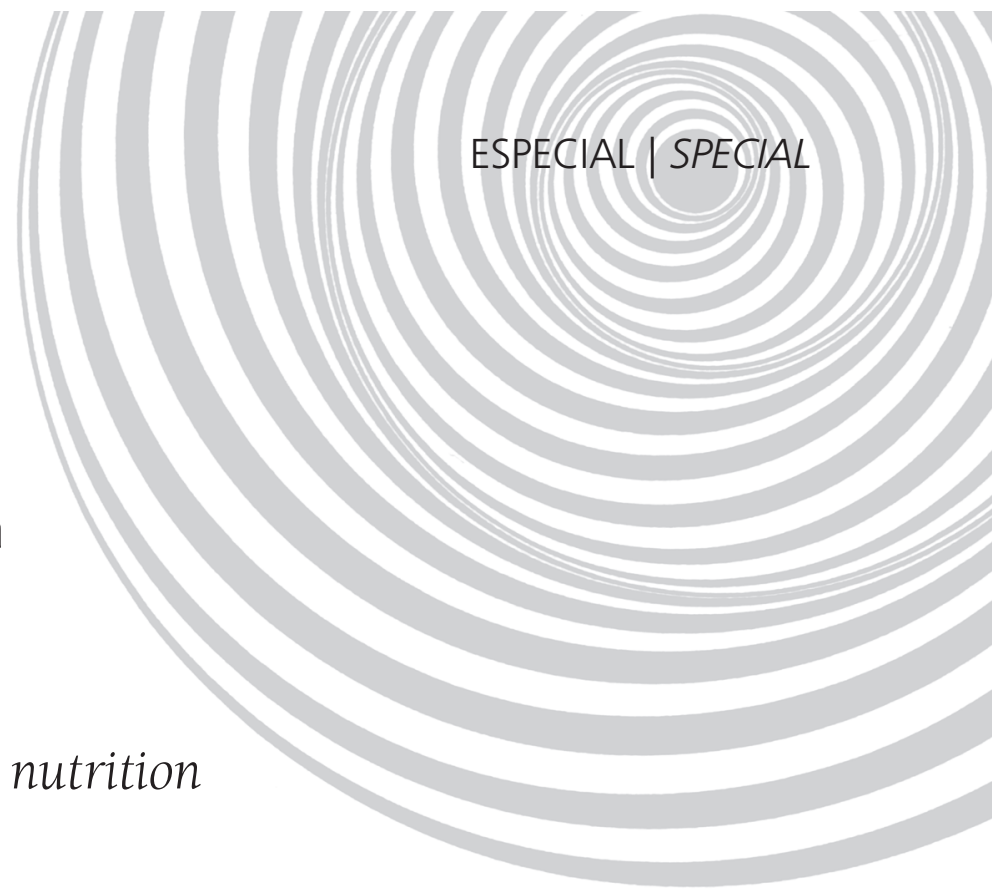

Francisco de Assis Guedes de VASCONCELOS ${ }^{1}$

RE S U M O

No cenário mundial, a emergência do campo da Nutrição foi um fenômeno característico do início do século XX. No Brasil, a emergência da Nutrição localizou-se na área das Ciências da Saúde (ou Ciências da Vida), caracterizando-se, à primeira vista, como uma ciência de natureza biológica. Este artigo tem por objetivo analisar a trajetória do processo de produção do conhecimento científico que garantiu especificidade ao campo da Nutrição no Brasil, da emergência aos dias atuais. Os pressupostos teóricos que norteiam o artigo são: o conceito de campo científico, desenvolvido por Pierre Bourdieu e os conceitos de paradigma e comunidade científica, introduzidos por Thomas Samuel Kuhn. A análise histórica evidencia que desde o seu nascimento, além da natureza biológica, a Nutrição brasileira assumiu dimensões sociais e ambientais, caracterizando-se como um campo de conhecimento multidisciplinar, constituído a partir da integração de Ciências Biológicas, Ciências Sociais e Ciências dos Alimentos e Nutrição. Nas últimas décadas, com o intenso desenvolvimento da comunicação e informática, da genética e das teorias sobre a sustentabilidade ecológica do planeta Terra, importantes mudanças paradigmáticas têm ocorrido no campo da Nutrição. Portanto, pode-se afirmar que a Nutrição estaria vivenciando a era pós-genômica, constituindo-se uma ciência multidisciplinar, caracterizada pela integração das dimensões biológica, social e ambiental.

Termos de indexação: Campo científico. Ciência da nutrição. Nutrição e dietética. Nutrigenômica. Paradigma.

A B S T R A C T

In the world scenario, the emergence of nutrition science was a phenomenon characteristic of the early Twentieth Century. In Brazil, its emergence occurred in the health sciences area (or life sciences) and was characterized, at first, as a science of biological nature. This article aims to analyze the trajectory of the process of producing scientific knowledge which ensured specificity to the field of nutrition in Brazil, from its emergence to the present. The theoretical assumptions that guide the article are: the concept of scientific field, developed by

\footnotetext{
1 Universidade Federal de Santa Catarina, Centro de Ciências da Saúde, Departamento de Nutrição. Campus Universitário. Trindade, 88040-970, Florianópolis, SC, Brasil.E-mail: <fguedes@floripa.com.br>.
} 
936 | F.A.G. VASCONCELOS

Pierre Bourdieu, and the concepts of paradigm and scientific community, introduced by Thomas Samuel Kuhn. Historical analysis shows that, from birth and in addition to its biological nature, Brazilian nutrition assumed social and environmental dimensions, being characterized as a multidisciplinary field of knowledge formed from the integration of the biological sciences, social sciences and food and nutrition sciences. In the last decades, with the intensive development of communication and information technology, genetics and sustainability theories, major paradigmatic changes have occurred in the field of nutrition. Therefore, one can say that nutrition is experiencing a post-genomic era and becoming a multidisciplinary science, characterized by the integration of the biological, social and environmental dimensions.

Indexing terms: Scientific field. Nutrition science. Nutrition and dietetics. Nutrigenomics. Paradigm.

\section{N T R O D U ÇÃ O}

Nas últimas três décadas, a historicidade do processo de emergência e consolidação do campo da Nutrição no Brasil foi objeto de distintas investigações ${ }^{1-6}$. Na literatura investigada observa-se um consenso em afirmar que, no cenário mundial, a emergência deste campo do saber científico foi um fenômeno característico do início do século $X X$. Também se identifica consenso nas afirmações de que as condições históricas para a constituição deste campo científico foram acumuladas ao longo da história da humanidade, estimuladas com a revolução industrial no século XVIII, e desencadeadas entre 1914 e 1945, período entre as duas Guerras Mundiais. Não obstante, o consenso observado na literatura parece ser abalado, quando se trata da periodicidade de eventos relacionados à constituição deste campo científico ${ }^{6,7}$.

Costa ${ }^{8}$ argumenta que o estatuto de ciência da Nutrição foi alcançado ao longo do desenvolvimento de três fases históricas consecutivas, por ele denominadas de períodos arcaico, pré-científico e científico, respectivamente. O período arcaico caracterizou-se pelo predomínio dos conhecimentos empíricos. O período pré-científico caracterizou-se pelo predomínio da Química, teria começado com as descobertas científicas do químico francês Antoine Laurent Lavoisier (1743-1794) e terminado, nos fins do século XIX, com as pesquisas do médico fisiologista alemão Carl Von Voit (1831-1908) e do químico norte-americano Wilbur Olin Atwater (1844-1907). O período científico caracterizou-se, inicialmente, por uma fase com predomínio da Fisiologia, a qual teria começado por volta de 1880, a partir dos estudos de calorimetria, e se prolongado até a Primeira Guerra Mundial. Na sequência, até a época da publicação do referido trabalho, transcorria uma fase ou período com predomínio de interesse econômico-social.

Chaves $^{9}$, por sua vez, faz referência à periodização que divide a história da Nutrição em três eras, denominadas de naturalística, químico-analítica e biológica. A era naturalística, circunscrita ao período de 400 a.C. até 1750 d.C., teria sido caracterizada pelo empirismo ou observação popular. A era químico-analítica, delimitada entre 1750 a 1900, caracterizou-se pelas grandes descobertas científicas, particularmente aquelas associadas a Lavoisier, considerado o pai da ciência da Nutrição. Por último, a era biológica, iniciada por volta de 1900 e que vigorava até a publicação do referido estudo, caracterizava-se pelas descobertas científicas relacionadas aos nutrientes, ao metabolismo e à fisiopatologia nutricional.

Nos dias atuais, conforme alguns estudos sobre essa temática, a Nutrição estaria vivenciando a era ou fase pós-genômica, constituindo-se uma ciência multidisciplinar, caracterizada pela integração de três dimensões: biológica, social e ambiental ${ }^{10-12}$.

Esse artigo tem por objetivo analisar a trajetória histórica do processo de produção do corpo de conhecimentos científicos que garantiu especificidade ao campo da Nutrição no Brasil, da emergência aos dias atuais.

Cabe explicitar que partimos de uma determinada concepção teórica que concebe campo científico como "um espaço de luta pelo mono- 
pólio da competência científica que é socialmente reconhecida a um agente determinado, ou seja, a capacidade técnica e o poder social de falar e intervir legitimamente em matéria de ciência"13 (p.131).

Ressaltamos ainda que, embora reconhecendo a dissonância entre a perspectiva sociológica reflexiva de Pierre Bourdieu (1930-2002) e a perspectiva filosófica idealista de Thomas Samuel Kuhn (1922-1996), é preciso explicitar a influência que também sofremos dos conceitos de paradigma e comunidade científica introduzidos por Kuhn ${ }^{14}$.

Sendo assim, nesse artigo a utilização do termo paradigma é feita dentro do seu sentido kuhniano como "realizações científicas universalmente reconhecidas que, durante algum tempo, fornecem problemas e soluções modelares para uma comunidade de praticantes de uma ciência"14 (p.13). Ou ainda, conforme esclarece o próprio autor ao abordar a circularidade dos conceitos de paradigma e comunidade científica: "um paradigma é aquilo que os membros de uma comunidade partilham e, inversamente, uma comunidade científica consiste em homens que partilham um paradigma"14 (p.219).

Na sequência, Kuhn apresenta sua concepção de como, em linhas gerais, ocorre a organização e o funcionamento da comunidade científica:

Uma comunidade científica é formada pelos praticantes de uma especialidade científica. Estes foram submetidos a uma iniciação profissional e a uma educação similares, numa extensão sem paralelos na maioria das outras disciplinas. Neste processo absorveram a mesma literatura técnica e dela retiraram muitas das mesmas lições. Normalmente as fronteiras dessa literatura-padrão marcam os limites de um objeto de estudo científico e em geral cada comunidade possui um objeto de estudo próprio'14 (p.220).

Complementando sua concepção idealista de comunidade científica como uma estrutura autônoma e autorreprodutora, onde os cientistas cooperariam de forma neutra e desinteressada em nome do progresso científico, Kuhn ${ }^{14}$ acrescenta que para compreender o conhecimento científico como propriedade intrínseca de uma determinada comunidade científica, torna-se necessário conhecer as características essenciais dessas unidades que o criam e o utilizam.

Bourdieu ${ }^{13,15}$, por sua vez, ao introduzir o seu conceito de campo científico, expressa claramente seu distanciamento da noção kuhniana de comunidade científica. Para ele, o campo científico constitui um mercado particular caracterizado pela luta concorrencial travada entre cientistas e/ou instituições científicas em torno da posse do capital científico - uma espécie de capital simbólico, não monetário, e que se transforma em autoridade/competência científica para os praticantes da ciência.

\section{A E MERGÊ N CIA D A N U TRIÇÃ O E D IETÉ TICA}

Como vimos anteriormente, no cenário mundial, o período compreendido entre 1914 a 1918 tem sido apontado como o contexto de emergência de ciência da Nutrição. A partir de então, os novos conhecimentos científicos sobre a alimentação humana propagaram-se entre diversos países, onde foram criados os primeiros centros de estudos e pesquisas, os primeiros cursos para formação de especialistas e as primeiras agências condutoras de medidas de intervenção em Nutrição ${ }^{1,2}$.

Na América Latina, a emergência da ciência da Nutrição ocorreu na década de 1920, sendo fortemente influenciada pelo médico argentino Pedro Escudero (1877-1963), criador do Instituto Nacional de Nutrição, da Escola Nacional de Dietistas e do Curso de Médicos Dietólogos da Universidade de Buenos Aires. As concepções de Escudero sobre este campo do saber, bem como sobre as características do processo de formação e atuação dos especialistas em Nutrição, foram difundidas em toda a América Latina, em função 
da concessão anual, a cada país latino-americano, de bolsas de estudos para a realização de Cursos de Dietética no Instituto Nacional de Nutrição da Argentina ${ }^{1,2,4,16}$.

No Brasil, a emergência do campo da Nutrição tem sido identificada ao longo das décadas de 1930 e 1940, contexto histórico que delimitou a implantação das bases para a consolidação de uma sociedade capitalista urbano-industrial no País ${ }^{1-3,6}$. Entretanto, desde a segunda metade do século XIX, o saber sobre a alimentação da população brasileira começou a despontar de forma mais sistematizada, a partir de teses apresentadas às duas faculdades de Medicina (Bahia e Rio de Janeiro) existentes até então no País $s^{6,7}$.

Nos primeiros anos da década de 1930, duas correntes do saber médico brasileiro confluíram-se para a constituição de um novo campo do saber - a Nutrição. Por um lado, aqueles que eram partidários da perspectiva biológica, preocupados essencialmente com aspectos clínico-fisiológicos relacionados ao consumo e à utilização biológica dos nutrientes e influenciados por concepções das Escolas de Nutrição e Dietética norte-americana e de centros europeus, surgidas no decorrer da Primeira Guerra mundial. Por outro lado, aqueles que compartilhavam das ideias da perspectiva social, preocupados particularmente com aspectos relacionados à produção, à distribuição e ao consumo de alimentos pela população e influenciados, particularmente, pelas concepções de Pedro Escudero. Ressalta-se que, naquela época, o termo Nutrologia foi a denominação mais utilizada para este novo campo do saber, derivado do campo da Medicina. Ao mesmo tempo, o termo nutrólogo foi a denominação mais utilizada para o especialista médico deste cam$\mathrm{po}^{1,2,6,17}$.

A partir da década de 1940, a perspectiva biológica deu origem a duas especializações dentro da Nutrição: Dietoterapia (Nutrição Clínica) e Nutrição Básica e Experimental. A Dietoterapia caracterizou-se por ser um campo de conhecimento voltado ao desenvolvimento de ações, de caráter individual, centradas no alimento como agente de tratamento. Enquanto a Nutrição Básica e Experimental caracterizou-se por ser um conjunto de conhecimentos voltados ao desenvolvimento de pesquisas básicas de caráter experimental e laboratorial relacionadas à alimentação humana ${ }^{3}$.

A perspectiva social, a partir da década de 1940, também deu origem a duas especializações dentro da Nutrição: Alimentação Institucional (ou Alimentação Coletiva) e Nutrição em Saúde Pública (ou Nutrição em Saúde Coletiva). A Alimentação Institucional caracterizou-se como uma especialização voltada à administração, no sentido de racionalização, da alimentação de coletividades sadias e enfermas. Enquanto a Nutrição em Saúde Pública caracterizou-se por um conjunto de conhecimentos voltados ao desenvolvimento de ações de caráter coletivo, no sentido de contribuir para garantir que a produção e distribuição de alimentos seja adequada e acessível a todos os indivíduos da sociedade ${ }^{3}$.

Assim, procurando garantir especificidade e legitimidade para este campo do saber científico que se constituía no País, os primeiros nutrólogos brasileiros, logo no início dos anos 1930, iniciaram o processo de produção e difusão de estudos e pesquisas sobre composição química e valor nutricional de alimentos nacionais, consumo, hábitos alimentares e estado nutricional da população brasileira. Da mesma forma, sobretudo a partir da segunda metade dos anos 1930, passaram a evidenciar certa organicidade intelectual com o Estado Nacional Populista, contribuindo na formulação das primeiras medidas de Política Social de Alimentação e Nutrição. Simultaneamente, trataram de criar os espaços institucionais necessários à formação dos novos agentes, seja por meio de estágios, viagens de estudos ou cursos realizados no exterior (Argentina, Europa Ocidental e EUA), seja a partir da criação dos primeiros cursos para formação de profissionais em Nutrição (nutrólogos, nutricionistas/dietistas, auxiliares de alimentação, economistas domésticas etc.). Com isso, procuraram estabelecer a demarcação das fronteiras definidoras dos limites de competência, de 
autonomia e de poder entre as distintas especialidades profissionais conformadoras do complexo e multidisciplinar campo da Nutrição que se constituía ${ }^{1,2,6}$.

Em relação ao processo de formação do nutricionista brasileiro, idealizado pela primeira geração de médicos nutrólogos, o mesmo teve seu início na década de 1940, quando foram criados os quatro primeiros cursos do País. As poucas análises realizadas sobre este processo de formação do nutricionista no Brasil apontam características históricas bastante específicas, apesar das influências externas sofridas, tanto das escolas norte-americana e europeias, como principalmente da escola argentina de Pedro Escudero. Conforme apontam alguns estudos, no Brasil o profissional surge (tanto) dentro do setor saúde, tendo como objeto de trabalho a alimentação do homem no seu plano individual ou coletivo (característica comum à sua origem nos demais países), como no setor de administração de serviços de alimentação do trabalhador (nos restaurantes populares do Serviço de Alimentação da Previdência Social - SAPS), por "vontade governamental, em momento de busca de legitimação social, constituindo-se em instrumento de alívio de tensões sociais" ${ }^{3}$ (p.21).

Outra característica específica deste início do processo de formação profissional foi quanto à adoção da terminologia nutricionista. A análise dos documentos de criação dos primeiros Cursos de Nutrição evidencia que o termo nutricionista era utilizado no Brasil desde 1939, conforme decreto de criação do Curso do Instituto de Higiene de São Paulo e documentos dos Cursos de Nutricionistas do SAPS e do Instituto de Nutrição da Universidade do Brasilit,6. Entretanto, no interior do campo de disputas estabelecidas no processo de constituição da Nutrição, o termo nutricionista também foi usado como designação das primeiras gerações de médicos nutrólogos brasileiros ${ }^{6}$. Ressalta-se ainda que, em sua fase inicial, o nutricionista era formado dentro de curso técnico de nível médio e chamado de dietista, a exemplo do que se verificava nos países da Europa, EUA e
Canadá. Aos poucos, os cursos brasileiros foram alterando estas características, aproximando-se das características do curso do Instituto Nacional de Nutrição da Argentina, "formando um profissional de nível universitário, com conhecimentos específicos de nutrição, com funções e responsabilidades próprias de atenção dietética ao indivíduo sadio ou enfermo, de forma individual ou coletiva" ${ }^{16}$ (p.53). Neste sentido, para alguns autores, no Brasil, rejeitou-se a utilização do termo dietista, que corresponde a um técnico de nível médio ou Auxiliar de Nutrição, optando-se pela denominação de nutricionista ${ }^{3}$. Entretanto, só em 1966, esta decisão foi oficializada internacionalmente, no decorrer da I Conferência sobre Adestramento de Nutricionistas-Dietistas de Saúde Pública, realizada em Caracas, na Venezuela (p.24).

Em síntese, no caso específico do Brasil, a emergência da Nutrição localizou-se na área das Ciências da Saúde (ou Ciências da Vida), caracterizando-se, à primeira vista, como uma ciência de natureza biológica. Entretanto, dada a complexidade que permeia o estudo das relações entre homens-natureza-alimento no interior das distintas sociedades humanas ${ }^{18}$, desde o seu nascimento a Nutrição brasileira assumiu outras dimensões de natureza sócio-cultural e ambiental, caracterizando-se como um campo de conhecimento multidisciplinar, constituído a partir da integração de Ciências Biológicas (Anatomia, Biologia, Fisiologia, Ecologia, Morfologia, Patologia etc.), Ciências Sociais (Administração, Antropologia, Economia, Geografia, Pedagogia, Psicologia, Sociologia etc.) e Ciências dos Alimentos e Nutrição (Bromatologia, Tecnologia de Alimentos, Higiene dos Alimentos, Técnica Dietética e Culinária, Dietoterapia, Administração dos Serviços de Alimentação, Nutrição Aplicada etc. $)^{19}$.

Neste sentido, no Brasil, esse complexo e multidisciplinar objeto de estudo da ciência da Nutrição foi inicialmente (com)partilhado entre distintos campos de conhecimentos e profissionais: Medicina (Nutrologia, Gastroenterologia, Endocrinologia, Pediatria), Enfermagem, Farmácia 
940 | F.A.G. VASCONCELOS

e Bioquímica, Agronomia, Administração, Economia, Antropologia, Sociologia etc. Nas décadas de 1970 e 1980, com a intensificação do desenvolvimento científico-tecnológico da indústria de alimentos, o campo da Nutrição brasileira passou a manter interface com mais dois outros campos de conhecimento: a Tecnologia e a Engenharia de Alimentos.

\section{NOVOS PARADIGMAS NUTRICIONAIS NO INIICIO DO S É CULOXXI: A E M ERG Ê NCIA DA NUTRIGENÔMICA}

A partir de meados da década de 1980, com a crise do chamado socialismo real, caracterizada, sobretudo pela queda do muro de Berlim e pela perestroika soviética, verificou-se o retorno à sociedade de mercado nos países socialistas. Teve fim a chamada guerra fria entre o bloco de países capitalistas centrais, liderados pelos Estados Unidos da América, e o bloco de países socialistas, liderados pela então União Soviética. No contexto internacional, começa a ser estabelecida uma nova ordem econômica caracterizada pelo avanço de princípios do neoliberalismo, com ênfase nos conceitos de indivíduo, mercado, equilíbrio espontâneo, produtividade, desestatização da economia, desregulamentação das relações de troca, estado mínimo, terceirização e globalização econômica ${ }^{18}$.

As duas últimas décadas do século XX também foram palco de outros importantes fenômenos, tais como o intenso desenvolvimento científico-tecnológico nos campos da comunicação e informática, da genética (mapeamento do genoma humano) e das teorias sobre a sustentabilidade ecológica do planeta Terra ${ }^{10-12,20}$. Neste contexto, se instalou o que se chamou de crise paradigmática, de busca de novos paradigmas ${ }^{21,22}$.

No campo da Nutrição brasileira, nas duas últimas décadas do século $X X$, também foram observadas importantes mudanças paradigmáticas. Observou-se que ao perfil epidemiológico nutricional que caracterizou a sociedade brasileira no período 1930-1980, constituído, sobretudo pelas doenças carenciais (desnutrição energético protéica, deficiência de vitamina A, pelagra, anemia ferropriva, deficiência de iodo etc.), sobrepuseram-se as doenças nutricionais crônico não transmissíveis (obesidade, diabetes, dislipidemias, hipertensão, certos tipos de câncer etc.), caracterizando o chamado fenômeno de transição nutricional e imprimindo a necessidade de construção de novos enfoques explicativos e intervencionais ${ }^{6,7}$. Neste aspecto, têm sido identificados distintos pontos de vista sobre este paradoxo nutricional brasileiro, tais como aqueles centrados no enfoque da transição epidemiológica nutricional ${ }^{23}$, na análise ecológica da obesidade e outras doenças não transmissíveis ${ }^{24}$, na concepção holística da Nutrição ${ }^{25}$, na abordagem fenomenológica da fome ${ }^{26}$, na visão sobre o direito humano à alimentação e nutrição ${ }^{27}$, no conceito e dimensões de espaço social alimentar ${ }^{28}$, nas representações sociais do consumo e das práticas alimentares ${ }^{29} \mathrm{e}$ mesmo na teoria da determinação social da doença ${ }^{30}$.

Simultaneamente, observou-se intensa ampliação do número de cursos e de nutricionistas no Brasil. De acordo com dados elaborados por Calado ${ }^{31}$, até maio de 2009, existiam 383 Cursos de Graduação em Nutrição no Brasil. Conforme dados do Conselho Federal de Nutricionistas $(C F N)^{32}$, até 31 de março de 2009, existia um contingente de 58465 nutricionistas no Brasil, perfazendo cerca de um nutricionista para cada 3725 habitantes. Portanto, com base em estudo anterior, entre 1989, quando existia um contingente de 11898 nutricionistas, e 2008, observou-se um aumento de 491,4\% no número de nutricionistas no Brasil 33

Como consequência do processo de intensa elevação do número de cursos e profissionais, nas últimas décadas também se observou intensa diversificação e ampliação das áreas de atuação do nutricionista no Brasil. De acordo com pesquisa realizada pelo CFN, em 2005, os nutricionistas brasileiros distribuíam-se em seis grandes áreas de atuação profissional com a seguinte preva- 
lência: Nutrição Clínica (41,7\%), Alimentação Coletiva (32,2\%), Saúde Coletiva (8,8\%), Ensino e Educação (9,4\%), Nutrição Esportiva (4,1\%) e Indústria de Alimentos $(3,7 \%)^{34}$. Atualmente, o Conselho Federal de Nutricionistas reconhece a existência de sete grandes áreas de atuação profissional do nutricionista: Nutrição Clínica, Alimentação Coletiva, Saúde Coletiva, Ensino e Educação, Nutrição Esportiva, Indústria de Alimentos e Marketing na área de Alimentação e Nutrição ${ }^{35}$.

Entretanto, observa-se que dentro de cada uma dessas grandes áreas de atuação profissional vai ocorrendo um amplo processo de divisão/ especialização dos seus objetos específicos de estudo e trabalho. Neste aspecto, na área de Nutrição Clínica, por exemplo, observam-se subáreas de atuação por patologias, grupos etários ou outras especializações, tais como a atuação do nutricionista em Oncologia, Nefrologia, Cardiologia, Diabetes, Transtornos Alimentares, Obesidade, Pediatria, Geriatria, Personal Diet, Consultórios e Clínicas, Hospitalização domiciliar etc. Na área de Alimentação Coletiva observa-se a expansão da atuação do nutricionista para setores específicos como Restaurantes comerciais, Fast food e similares, Assessoria em Supermercados e Padarias, Hotelaria, SPA, Controle de Qualidade e Vigilância Sanitária etc. A Nutrição em Saúde Coletiva, por sua vez, consolida e amplia a área de atuação do nutricionista no campo das políticas públicas, tais como no Programa Nacional de Alimentação Escolar (PNAE), no Programa de Alimentação do Trabalhador (PAT), na Estratégia Saúde da Família, a partir da criação dos Núcleos de Atenção à Saúde da Família (NASF) etc. De forma semelhante, a recente área de atuação profissional do nutricionista - Nutrição Esportiva - ocupa os espaços das academias e de distintas modalidades esportivas no país (futebol, vôlei, natação, atletismo etc. $)^{36}$.

Nos dias atuais, o objeto de estudo da Nutrição tem sido (com)partilhado por distintas ciências e profissionais, denotando cada vez mais a ampliação do seu caráter multidisciplinar. Entre os novos campos disciplinares que a partir dos anos 1990 passaram a fazer interfaces com a Nutrição, destacam-se a Gastronomia, a Nutracêutica e a Nutrigenômica.

Os cursos superiores de Gastronomia surgiram no Brasil a partir do final da década de 1990, tendo sua expansão nos primeiros anos 2000. Entre fevereiro de 1999, mês de criação do primeiro curso até abril de 2008, foram identificados 36 Cursos de Gastronomia em funcionamento no País. A maioria desses cursos caracteriza-se por ser uma graduação tecnológica com área profissional focalizada em turismo e hotelaria (hospitalidade) ${ }^{37}$.

A Nutracêutica, termo introduzido em 1989 por Stephen DeFelice a partir da conjunção dos conceitos de Nutrição e Farmacêutica, se constitui em um novo campo científico cujo objeto de estudo é a investigação dos componentes fitoquímicos presentes nos alimentos e plantas medicinais e sua influência na promoção da saúde, prevenção e tratamento de doenças ${ }^{38}$. Simultaneamente, também tem sido difundido o conceito de alimento funcional, o qual é definido pela Agência Nacional de Vigilância Sanitária (ANVISA), órgão do Ministério da Saúde, como "O alimento ou ingrediente que alegar propriedades funcionais ou de saúde pode, além de funções nutricionais básicas, quando se tratar de nutriente, produzir efeitos metabólicos e ou fisiológicos e ou efeitos benéficos à saúde, devendo ser seguro para consumo sem supervisão médica" ${ }^{39}$.

A Nutrigenômica, por sua vez, tem sido considerada um novo campo científico que começou a se constituir no interior da Nutrição a partir dos avanços científicos verificados no campo da genética e do mapeamento do genoma humano, anunciado nos meios de comunicação em junho de 2000. No Brasil, observa-se também a utilização de um termo variante - Nutrogênomica. Embora não se tenha investigado as origens históricas e etimológicas dos dois termos, pressupõe-se que a expressão Nutrigenômica represente a conjunção dos conceitos de Nutrição e Genômica, enquanto Nutrogenômica represente a conjunção dos conceitos de Nutrologia e Genômica. 
942 F.A.G. VASCONCELOS

A Nutrigenônica tem sido definida como a ciência que estuda a interação entre os nutrientes e os genes humanos. Ou seja, estuda a forma pela qual o DNA e o código genético influenciam a determinação das necessidades nutricionais e o metabolismo de nutrientes de cada indivíduo. Portanto, parte da premissa de que os distintos nutrientes constituintes da dieta desempenham diferentes papéis ou funções nutricionais em cada indivíduo, conforme sua herança ou código genético. Sendo assim, com o avanço da Nutrigenômica abre-se a perspectiva de prescrição e elaboração de dietas personalizadas de acordo com a composição genética individual, ampliando-se as estratégias disponíveis no sistema de promoção da saúde e de prevenção e tratamento de doenças como diabetes mellitus tipo 2, obesidade, cardiovasculares e certos tipos de câncer ${ }^{12,40-42}$.

Enfim, diante da globalização da Nutrição e/ou das doenças nutricionais, onde a produção, a circulação e o consumo da mercadoria alimento permanecem atrelados às necessidades de acumulação do capital e não às necessidades nutricionais humanas, novos dilemas nos são colocados nestas primeiras décadas do Século XXI6.

Um destes dilemas, por um lado, diz respeito ao fenômeno chamado de McDonaldização dos hábitos alimentares ${ }^{43}$ que, grosso modo, pode ser concebido como uma possível tendência à uniformização planetária de hábitos e práticas alimentares, sobretudo a partir da adoção da chamada dieta ocidental ou da ocidentalização do padrão de consumo alimentar. Padrão este, particularmente caracterizado por uma dieta rica em gorduras (sobretudo, as de origem animal) e em carboidratos simples (açúcar e alimentos refinados) e pobre em carboidratos complexos e fibras. Este fenômeno de ocidentalização do consumo alimentar, aliado a outros fatores do estilo de vida ocidental, tais como o sedentarismo, têm sido associados ao aumento da prevalência da obesidade e demais doenças não transmissíveis ${ }^{23}$. Por outro lado, também diz respeito ao chamado movimento Slow Food. O movimento Slow Food surge, em meados dos anos 1980, como "resposta aos efeitos padronizantes do fast food; ao ritmo frenético da vida atual; ao desaparecimento das tradições culinárias regionais; ao decrescente interesse das pessoas na sua alimentação, na procedência e sabor dos alimentos e em como nossa escolha alimentar pode afetar o planeta" 44 . Simultaneamente, também diz respeito às tentativas de difusão ou de transposição de modelos de dietas consideradas como responsáveis pelos elevados padrões de vida longa e saudável de determinadas populações, tais como as chamadas dieta mediterrânea e dieta asiática ou oriental ${ }^{45}$.

Vale ressaltar que a partir de 2002 a OMS desencadeou o processo para a construção da "Estratégia Global sobre Alimentação Saudável, Atividade Fisica e Saúde", tendo por objetivo a prevenção e controle das doenças crônicas não transmissíveis, a qual foi aprovada em sua $57^{\text {a }}$ Assembléia Mundial de Saúde ${ }^{46}$. A partir de então, o conceito de Alimentação Saudável passou a ser um dos novos paradigmas do campo da Nutrição nestes primórdios do século XXI. No Brasil, as estratégias para a adoção de uma Alimentação Saudável foram imediatamente incorporadas pelo Ministério da Saúde e estão sendo difundidas a partir de diversas publicações e outros mecanismos de divulgação ${ }^{47}$.

Outro dilema da atualidade diz respeito ao paradigma da segurança/insegurança alimentar, o qual está intimamente relacionado às teorias da (in)sustentabilidade ecológica do planeta e ao princípio do direito humano à alimentação 11,20,27. A controvertida "crise mundial dos alimentos", divulgada nos meios de comunicação nos primeiros meses de $2008^{48,49}$, traz novamente à tona o debate sobre velhos fantasmas da humanidade: crescimento populacional versus produção e consumo de alimentos; uso irracional dos recursos finitos da natureza versus poluição e degradação ambiental; elevação dos níveis de aquecimento global versus estratégias para redução da emissão de gás carbônico; interesses 
político-econômicos versus direitos humanos. Portanto, assumindo o princípio da corresponsabilidade social, torna-se imperante para a Ciência e os cientistas da Nutrição a nossa incorporação à luta pela adoção de um modelo de desenvolvimento econômico mundial sustentável, ou seja, aquele que deverá ocorrer em harmonia com as limitações ecológicas do planeta, sendo capaz de suprir as necessidades da geração atual, sem comprometer a capacidade de atender as necessidades das futuras gerações ${ }^{50}$.

\section{O N CLUS Ã O}

Diante de tais dilemas, cumpre-nos o papel de não apenas procurar identificar e respaldar um padrão dietético que garanta uma vida digna e saudável para todos os brasileiros, mas que busque a preservação da nossa diversidade bio-etnocultural e a garantia da identidade nacional.

Neste sentido, vale a pena propor uma reflexão coletiva sobre algumas questões inerentes ao processo de formação acadêmica e, por consequência, à prática profissional do nutricionista no Brasil: o atual processo de formação profissional possibilita ao nutricionista o desenvolvimento das habilidades e competências necessárias ao exercício de uma ciência da Nutrição pós-genômica, multidisciplinar e caracterizada pela integração de dimensões biológicas, sociais e ambientais? Os conteúdos das diretrizes curriculares dos Cursos de Nutrição implantados dentro dos projetos pedagógicos, idealizados a partir da instituição da Lei de Diretrizes e Bases da Educação Brasileira de 1996, conseguem abordar as habilidades e competências para atuação qualificada nas distintas áreas de atuação profissional?

Enfim, a reflexão coletiva proposta exige a participação compartilhada e corresponsável de nutricionistas, estudantes de Nutrição, professores de Nutrição, coordenadores de cursos de graduação e pós-graduação em Nutrição e suas entidades representativas (conselhos, associações científico-culturais, sindicatos etc.).

\section{REFERÊ NCIAS}

1. Coimbra M, Meira JFP, Starling MBL. Comer e aprender: uma história da alimentação escolar no Brasil. Brasília: Ministério da Educação e Cultura; 1982.

2. L'Abbate S. As políticas de alimentação e nutrição no Brasil. I. Período de 1940 a 1964. Rev Nutr. 1988; 1(2):87-138.

3. Ypiranga L, Gil MF. Formação profissional do nutricionista: por que mudar? In: Cunha DTO, Ypiranga L, Gil MF, organizadores. Anais do II Seminário Nacional sobre o Ensino de Nutrição. Goiânia: Federação Brasileira de Nutrição; 1989.

4. Associação Brasileira de Nutrição. Histórico do nutricionista no Brasil - 1939 a 1989: coletânea de depoimentos e documentos. São Paulo: Atheneu; 1991.

5. Costa NMSC. Revisitando os estudos e eventos sobre a formação do nutricionista no Brasil. Rev Nutr. 1999; 12(1):5-19. doi: 10.1590/S1415-527 31999000100001.

6. Vasconcelos FAG. O nutricionista no Brasil: uma análise histórica. Rev Nutr. 2002; 15(2):127-138. doi: 10.1590/S1415-52732002000200001.

7. Vasconcelos FAG. Tendências históricas dos estudos dietéticos no Brasil. Hist Ciênc Saúde - Manguinhos. 2007; 14(1):197-219.

8. Costa D. A Importância do ensino da nutrição: o seu desenvolvimento no Brasil. Rev Bras Med. 1953; 10(9):645-50.

9. Chaves N. História da nutrição e da alimentação. In: Chaves N. Nutrição básica e aplicada. Rio de Janeiro: Guanabara Koogan; 1978.

10. Cannon G, Leitzmann C. The new nutrition science project. Public Health Nutr. 2005; 8(6A):673-94.

11. McMichael AJ. Integrating nutrition with ecology: balancing the health of humans and biosphere. Public Health Nutr. 2005; 8(6A):706-15.

12. Afman L, Müller M. Nutrigenomics: from molecular nutrition to prevention of disease. J Am Diet Assoc. 2006; 106:569-76.

13. Bourdieu P. El campo científico. Rev Estud Sociales Cienc. 1994; 1(2):131-60.

14. Kuhn TS. A estrutura das revoluções científicas. $5^{a}$ ed. São Paulo: Perspectiva; 1997.

15. Bourdieu P. O poder simbólico. $2^{\text {a }}$ ed. Rio de Janeiro: Bertrand Brasil; 1998.

16. Icaza SJ. Evolución histórica de la formación del nutricionista-dietista en América Latina. Memoria 
944 | F.A.G. VASCONCELOS

da Reunión de CEPANDAL, 4, Memória. San Juan, Puerto Rico: OPAS: INCAP; 17 a 20 de septiembre de 1991.

17. Maurício HV. Evolução da nutrição e do seu ensino no Brasil. Arq Bras Nutr. 1964; 20(2):117-34.

18. Vasconcelos FAG. Avaliação nutricional de coletividades. $4^{a}$ ed. Florianópolis: Editora da UFSC; 2007.

19. Brasil. Ministério da Educação e Cultura. Os cursos de nutrição no Brasil: evolução, corpo docente e currículo. Brasília; 1983. Série de Cadernos de Ciências da Saúde, 6.

20. Food and Agriculture Organization. The state of food insecurity in the world. Rome: FAO; 2004.

21. Souza Santos B. Um discurso sobre as ciências. $7^{\text {a }}$ ed. Porto: Afrontamento; 1995.

22. Singer P. Ética prática. São Paulo: Martins Fontes; 1994.

23. Monteiro CA, Mondini L, Souza ALM, Popkin BM. Da desnutrição para a obesidade: a transição nutricional no Brasil. In: Monteiro CA, organizador. Velhos e novos males da saúde no Brasil: a evolução do país e de suas doenças. $2^{a}$ ed. São Paulo: Hucitec; 2000.

24. Sichieri R, Everhart JE, Mendonça GAS. Diet and mortality from common cancers in Brazil: an ecological study. Cad Saúde Pública. 1996; 12(1):53-9.

25. Bosi MLM. A Nutrição na concepção científica moderna: em busca de um novo paradigma. Rev Nutr. 1994; 7(1):32-47.

26. Freitas MCS. Uma abordagem fenomenológica da fome. Rev Nutr. 2002; 15(1):53-69. doi: 10.1590/S14 15-52732002000100007.

27. Valente FLS, organizador. Do direito humano à alimentação: desafios e conquistas. São Paulo: Cortez; 2002.

28. Poulain JP, Proença RPC. O espaço social alimentar: um instrumento para o estudo dos modelos alimentares. Rev Nutr. 2003; 16(3):245-56. doi: 10.1590/S 1415-52732003000300002.

29. Garcia RWD. Representações sobre consumo alimentar e suas implicações em inquéritos alimentares: estudo qualitativo em sujeitos submetidos à prescrição dietética. Rev Nutr. 2004; 17(1):15-28. doi: 10.1590/S1415-52732004000100002.

30. Escoda MSQ. Para a crítica da transição nutricional. Cien Saúde Coletiva. 2002; 7(2):219-26.

31. Calado CLA. Relação de endereços dos cursos de nutrição no Brasil: maio 2009 [acesso 2009 jul. 10]. Disponível em: <http://www.cfn.org.br/novo site/ arquivos/cursos_nutricao_maio_2009.pdf>.
32. Brasil. Conselho Federal de Nutricionistas. Estatísticas: quadro estatístico do $1^{\circ}$ trimestre/2009 (1\% 01/2009 a 31/03/2009). [acesso 2009 jul 23]. Disponível em: <http://www.cfn.org.br/novosite/ arquivos/ESTATISTICO-1-TRIMESTRE-2009.pdf>.

33. Vasconcelos FAG, Rossi CE, Costa M. Evolução histórica do nutricionista em Santa Catarina (1980-2003). Rev Cien Saúde. 2005; 24(1/2):28-35.

34. Brasil. Conselho Federal de Nutricionistas. Inserção profissional dos nutricionistas no Brasil. Brasília: CFN; 2006.

35. Brasil. Conselho Federal de Nutricionistas. Resolução CFN n 380/2005. Dispõe sobre a definição das áreas de atuação do nutricionista e suas atribuições, estabelece parâmetros numéricos de referência por área de atuação e dá outras providências [acesso 2009 jul 20]. Disponível em: <http://www. cfn.org.br/novosite/pdf/res/2005/ res380.pdf>.

36. Brasil. Conselho Federal de Nutricionistas. Profissão de nutricionista completa 40 anos de regulamentação. Revista do CFN. 2007; 5(21):8-9.

37. Associação Brasileira da Alta Gastronomia. Cursos de gastronomia no Brasil. [acesso 2008 maio 2]. Disponível em: <http://www.abaga.com.br/ modules. php ? name $=$ Sections \&sop=viewarticle \&artid $=4406>$.

38. Kalra E. Nutraceutical: definition and introduction. AAPS PharmSci. 2003; 5(3): 1-2. [cited 2008 May 3]. Available from: <http://www.aapspharmsci.org/ articles/ps0503/ps050325/ps050325.pdf>.

39. Agência Nacional de Vigilância Sanitária. Resolução n 18, de 30 de abril de 1999. Aprova o Regulamento Técnico que estabelece as diretrizes básicas para análise e comprovação de propriedades funcionais e ou de saúde alegadas em rotulagem de alimentos. [acesso 2008 maio 3]. Disponível em: http://e-legis.anvisa.gov.br/leisref/public/ showAct.php?id=109>.

40. Kaput J, Noble J, Hatipoglu B, Kohrs K, Dawson K, Bartholomew A. Application of nutrigenomic concepts to Type 2 diabetes Mellitus. Nutr Metab Cardiovasc Dis. 2007; 17:89-103.

41. Simopoulos AP. Genetic variation and dietary response: nutrigenetics/nutrigenomics. Asia Pacific J Clin Nutr. 2002; 11(S6):S117-S28.

42. Fialho E, Moreno, FS, Ong TP. Nutrição no pós-genoma: fundamentos e aplicações de ferramentas ômicas. Rev Nutr. 2008; 21(6):757-66. doi: 10. 1590/S1415-52732008000600014.

43. Fischler C. A "McDonaldização" dos costumes. In: Flandrin JL, Montanari M. História da alimentação. São Paulo: Estação Liberdade; 1998. 
44. Slow Food Brasil. Bem-vindo ao Slow Food Brasil! [acesso 2008 maio 3]. Disponível em: <http://www. slowfoodbrasil.com/component/option.com_ frontpage/ltemid,1/>.

45. Garcia RWD. Dieta mediterrânea: inconsistências ao se preconizar modelos de dieta. Cad de Debate, 2001; 8:28-36.

46. World Health Organization. Global strategy on diet, physical activity and health. Geneva: WHO; 2004 [cited 2008 May 2]. Available from: <http://www. who.int/gb/ebwha/pdf_files/WHA57/A57_R17en.pdf>.

47. Brasil. Ministério da Saúde. Guia alimentar para a população brasileira: promovendo a alimentação saudável. Brasília: MS; 2006 [acesso 2008 maio 2]. Disponível em: <http://dtr2004.saude.gov.br/ nutricao/documentos/guia_alimentar_conteudo. pdf $>$.

48. Guimarães L. Entenda a crise mundial dos alimentos. [acesso 2008 maio 5]. Disponível em: <http:// www.ambientebrasil.com.br/noticias/index.php3? action=ler\&id=37837>.

49. Biodieselbr. Os biocombustíveis vão produzir escassez de alimentos? [acesso 2008 maio 5]. Disponível em: <http://www.biodieselbr.com/ noticias/biodiesel/r1-biocombustiveis-escassezalimentos-21-04-08.htm>.

50. Comissão Mundial sobre Meio Ambiente e Desenvolvimento. Nosso futuro comum. $2^{\text {a }}$ ed. Rio de Janeiro: Fundação Getúlio Vargas; 1991.

Recebido em: 8/6/2010

Aprovado em: 12/8/2010 
